\title{
O CRESCIMENTO DO CONHECIMENTO E A LACUNA DISCURSIVA*
}

\author{
Roв Moore* \\ JoHAN MULLER ${ }^{* * *}$ \\ We are told and socialized into what to reject, but rarely \\ told how to create.**** \\ (Somos ensinados e socializados com relação ao que rejei- \\ tar, mas raramente somos ensinados a criar.)
}

(Basil Bernstein, 1977, p. 167)

RE SU M 0 : Este artigo discute a questão do caráter da teoria de Bernstein. Ele baseia-se em um conjunto de conceitos-chave elaborados em alguns de seus artigos mais recentes, embora sugira ser possível discernir as origens dessas idéias em trabalhos muito mais antigos. Na primeira seção discute-se 0 diagnóstico de Bernstein, que compreende a sociologia da educação como uma estrutura do conhecimento horizontal com uma gramática fraca. D estaca-se um aparente paradoxo: se a sociologia da educação tem essa forma, como podemos explicar a própria teoria de Bernstein? 0 resto do texto emprega os próprios trabalhos de Bernstein como uma maneira de explorar as condições para o crescimento do conhecimento em sociologia como uma estrutura do conhecimento vertical com uma gramática forte.

Palavras-chave: Teorias de Bernstein. Teoria da sociologia da educação. Teoria da sociologia do conhecimento. Teoria sociológica.

\footnotetext{
* Tradução de Alain François, com revisão técnica de Antonio Flávio Barbosa Moreira.

* Faculdade de Educação da Universidade de Cambridge (EUA). E -mail: rm233@ cam.ac.uk

** Departamento de Educação da Universidade de Cape Town (EUA).

E-mail: jpm@ education.uct.ac.za

* *k* "Dizem-nos e socializam-nos no que rejeitar, mas raramente nos dizem como criar."
} 


\title{
THE GROWTH OF KNOWLEDGE AND THE DISCURSIVE GAP
}

\begin{abstract}
A BSTRA CT: This paper raises the question of the character of Bernstein's theory. It draws upon a set of key concepts elaborated in some of his later papers, though we suggest that it is possible to discern the origins of these ideas in much earlier work. In the first section Bernstein's diagnosis of the sociology of education as a horizontal knowledge structure with a weak grammar is discussed and an apparent paradox identified: if the sociology of education has this form, how can we account for Bernstein's own theory? The remainder of the paper uses the case of Bernstein's own work as a way of exploring the conditions for knowledge growth in sociology as a vertical knowledge structure with a strong grammar.
\end{abstract}

Key words: Bernstein's theories. Sociology of education. Sociology of knowledge. Sociological theory.

\section{Introdução}

A

o fazer um balanço de seus 35 anos de pesquisa, Bernstein (2000, P. 93) disse: "A teoria, por mais primitiva que seja, sempre vem antes da pesquisa. Portanto, assim que se inicia uma pesquisa, a teoria já foi sujeita a um esclarecimento conceitual antes de se envolver com o problema empírico. E no momento em que acaba, ocorreram mais desenvolvimentos conceituais". Aqui, nossa pergunta é justamente: 0 que vem a ser "a teoria"? Não a formulamos no seu sentido mais usual de "que é a teoria da família elaborada por Bernstein"? $\mathrm{Ou}$ "a teoria de Bernstein é estruturalista"? Antes, nossa pergunta se aproxima mais de: "Como a teoria funciona e que tipo de teoria é essa que funciona dessa maneira"? O que faz a teoria quando "se envolve com o problema empírico"? O uso que Bernstein faz do verbo "envolver-se" é significativo e, nas palavras citadas acima, o autor parece estar tratando a teoria como um processo, como uma prática. Ela não simplesmente descreve ou representa a realidade; ela envolvese diretamente com ela, entra em relação com ela. Em alguns de seus artigos mais recentes (por exemplo, ibid., Caps. 6, 7 e 9), Bernstein começou a desenvolver uma nova linguagem para pensar a respeito da teoria - uma teoria de teorias - assim como os conceitos para uma nova e mais ampla sociologia dos campos intelectuais, para uma abrangente sociologia do conhecimento. No que segue, vamos nos basear nessa linguagem. 
Tentaremos responder a nossa pergunta colocando-a de novo em termos de como a teoria de teorias de Bernstein descreveria sua própria teoria e como esta, por sua vez, trata da questão de como o conhecimento sociológico cresce. Nisto, há dois aspectos. 0 primeiro diz respeito ao diagnóstico de Bernstein referente à sociologia como um campo do conhecimento e o segundo, à sua explicação do crescimento do conhecimento sociológico. Juntos, eles levam à pergunta: Q uais são as perspectivas e as condições para 0 avanço do conhecimento em nossa disciplina? Hoje em dia, temos, por um lado, os popperianos com sua explicação do avanço metódico por meio da sucessão de conjecturas e refutações, e por outro, o cepticismo pós-moderno generalizado quanto à possibilidade de todo e qualquer progresso do conhecimento. Veremos que a posição de Bernstein é muito mais flexível e matizada que esses dois pontos de vista. Conseqüentemente, o presente ensaio não se limita a expor ou a fazer a exegese das idéias de Bernstein. Existe uma questão mais profunda e mais ampla que diz respeito às possibilidades da sociologia da educação e da sociologia em geral.

Essas preocupações são de suma importância na educação, em que o problema do conhecimento se coloca em termos do que ensinar e dos propósitos da indução ao conhecimento. Já há algum tempo que os debates tanto na sociologia da educação como na própria educação estão enclausurados numa "configuração-padrão" orientada pela polaridade tradicional/ progressivista (Muller, 2001). Mais recentemente 0 viés "antiteoria" dos progressivistas se fortaleceu graças a um leque de perspectivas pós-modernas e multiculturais que elevam o relativismo a uma posição de princípio e confinam o conhecimento exclusivamente no plano das experiências especializadas conforme identidades e pontos de vista particulares (em outro texto nos referimos a elas como aos "discursos das vozes" [Moore \& Muller, 1999]). O conhecimento é reduzido às políticas de identidade e reconhecimento, nas quais as relações de conhecimento são simplesmente representadas como relações de poder entre grupos. Repelir o pós-modernismo não significa apenas acrescentar mais uma abordagem (um conjunto de perspectivas sociais críticas realistas [Moore \& Young, 2001]) a todas as que já integram a coleção sociológica, mas reorientar o campo em que essa coleção e as relações entre seus elementos possam ser entendidas de modo bem diferente. É a esse ponto que a teoria de Bernstein traz uma contribuição crucial. 
A condição da sociologia da educação - diagnóstico

Bernstein preocupava-se com o caráter conceitualmente fraco do conhecimento na sociologia e na sociologia da educação. Os conceitos que desenvolveu descrevem, numa linguagem teórica, a condição de um campo intelectual caracterizado pela fragmentação, cuja história é uma proliferação sucessiva de subdisciplinas e perspectivas ou abordagens, e que não consegue assegurar uma teoria geral integrativa ou produzir conhecimento cumulativo. Sua teoria abre a perspectiva de podermos ver a sociologia da educação e pensarmos sobre suas divisões internas e debates de uma maneira inteiramente nova, que dispensa as caracterizações e dicotomias tradicionais e atuais e as substitui por uma nova linguagem teórica que descreve o campo conceitualmente em termos de sua condição.

Embora tenhamos afirmado acima que Bernstein começou a formular seus conceitos para as estruturas do conhecimento em alguns de seus artigos mais recentes, foi numa revisão da sociologia da educação, no começo dos anos de 1970, que ele apresentou pela primeira vez uma explicação extensa do campo em que os conceitos ulteriores têm sua provável origem (Bernstein, 1977, Cap. 7). Vale recorrer a essa explicação mais antiga para ilustrar tanto a continuidade dessa linha de pensamento em seu trabalho quanto a maneira como o campo da sociologia da educação permaneceu preso a uma modalidade dominante particular durante esse longo período de tempo. Partiremos da descrição do que, na conceituação mais recente, pode ser reconhecido como uma "estrutura de conhecimento horizontal e segmentada com uma gramática fraca”.

Numa disciplina em que as teorias e os métodos são fracos, é mais provável que as mudanças intelectuais surjam do conflito entre abordagens que de um conflito entre explicações, pois, por definição, as explicações, em sua maioria, serão fracas e muitas vezes não comparáveis, pois são dependentes das abordagens. A fraqueza da explicação deve provavelmente ser atribuída à abordagem, que é analisada em termos de sua postura ideológica. Uma vez exposta a postura ideológica, todo o trabalho pode ser descartado. Cada nova abordagem se torna um movimento ou uma seita social que define imediatamente a natureza da disciplina ao redefinir o que deve ser admitido e o que é inaceitável, de modo que, a cada nova abordagem, a disciplina quase recomeça do zero... Uma nova opção é criada, e a coleção da sociologia amplia-se 
para incluir umas identidades um pouco mais especializadas: etnometodológica, interacionista simbólica, fenomenológica, estruturalista. (Bernstein, 1977, p. 167-168)

D e fato, o campo da sociologia, hoje em dia, apresenta esta estrutura segmentar de maneira ainda mais intensa que há 30 anos. Com as influências pós-moderna e pós-estruturalista, a segmentação tem-se tornado uma condição que deve ser buscada conscientemente e exaltada em termos de reconhecimento e afirmação de "identidades" e "pontos de vista". Ainda que, na época em que escreveu, Bernstein nomeasse as abordagens com uma nomenclatura teórica, hoje, este mesmo exercício poderia ser, de modo significativo, realizado por uma dessas identidades "hifenizadas" em que a abordagem é desenvolvida por quem sabe em vez de prover uma identidade para quem sabe (Bernstein, 1977, p. 106-110). Neste ponto, o campo segmentado torna-se cada vez mais instável porque, em princípio, não há fim para a proliferação das "vozes" correspondentes a identidades cada vez mais especializadas ("hifenizadas") (Maton, 2000). A conseqüência é que a acumulação de conhecimento fica, por definição, impedida de ocorrer.

É então possível distinguir duas maneiras muito diferentes de descrever os campos intelectuais. Na primeira, as abordagens são "nomeadas" em termos das características de organização de sua perspectiva ("funcionalista", "estruturalista" etc.) ou diretamente pelas perspectivas, em termos do ponto de vista ou dos interesses que dizem representar (como quando o conhecimento é designado como "machista", "feminista" ou "autóctone"). Na segunda, suas formas de estrutura e conhecimento são conceituadas em termos de suas modalidades. Nesse segundo caso, como Bernstein costumava frisar, o foco também está mais nas relações internas ao conhecimento que naquelas unicamente externas a ele - por exemplo, unicamente sobre as propriedades relacionais do campo e de suas posições, trajetórias e estratégias, como em Bourdieu, ou no reducionismo de pontos de vista e interesses de abordagens teóricas. Os campos de produção de conhecimento podem operar de modos diferentes. É a modalidade que conforma a produção de teorias e, conseqüentemente, de conhecimento no campo e, assim, constrói as identidades dos "praticantes" do campo, define que problema deve ser discutido e como discuti-lo. É 
na conceituação de modalidades em oposição à nomeação de perspectivas que Bernstein trouxe uma contribuição radical.

Em sua análise clássica, Bernstein começa por distinguir o discurso horizontal do vertical. O primeiro é o discurso de "todos os dias", e consiste em um reservatório de segmentos locais compartilhados e definidos em contextos de uso. 0 discurso vertical consiste em uma "estrutura coerente, explícita e com princípios sistemáticos", seja hierarquicamente organizada, como nas ciências (estrutura hierárquica de conhecimento), ou revestindo a forma de uma série de linguagens especializadas, como nas ciências sociais e humanas (estrutura horizontal de conhecimento) (Bernstein, 2000, p. 157). A sociologia da educação é, então, uma estrutura de conhecimento horizontal com uma gramática fraca, com uma sintaxe conceitual incapaz de gerar descrições empíricas precisas e sem ambigüidades. E como essa gramática não consegue relacionar as descrições empíricas com as descrições teóricas sem controvérsias, a descrição empírica não pode arbitrar disputas conceituais. Conseqüentemente, quando surgem disputas, uma nova linguagem especializada é invariavelmente criada porque não existe um princípio geralmente aceito para integrar as teorias em disputa existentes. D o mesmo modo, não existem meios geralmente aceitos para se livrar das velhas teorias antiquadas que começam a estorvar a literatura.

Embora a segmentação envolva uma ênfase na "distintividade" (distinctiveness) e na diferença, especialmente quando a condição é expressa por meio da retórica do pós-modernismo, em termos de estrutura, cada segmento em uma estrutura de conhecimento horizontal tem a mesma forma. As diferenças entre os "clãs" são emblemáticas cada um adora seu próprio totem (um constructo de sua própria identidade, por exemplo as variedades de pós-colonialismo especializado por identidades "hifenizadas"), mas cada um reproduz a forma dos outros, simplesmente especializada, de maneira reducionista, por uma identidade diferente. Não que haja mais o que dizer, pelo contrário, crescem as fileiras dos que vêm dizer a mesma coisa. Essa reprodução mecânica continua tanto proclamando uma ruptura radical com 0 passado (as teorias "pós") quanto rompendo, pela criação de novo cisma, com uma "igreja" (teorias baseadas em "pontos de vista") estabelecida (tendência dominante/ tendência machista [mainstream/ malestream]) (Moore, 1996; Moore \& Maton, 2002). 
Recapitulando, a sociologia, num modo de conhecimento horizontal, progride não de maneira cumulativa, mas pela expansão lateral de linguagens especializadas, as quais têm poderes limitados de extensão vertical para acumular o que Collins chama de "seqüências de abstração-reflexividade". Os conceitos de Bernstein possibilitam dois tipos diferentes de descrição dos campos intelectuais - numa linguagem, a descrição dá-se em termos das perspectivas e atividades de seus membros: os tipos de coisas que são definidas como "problemas", as maneiras de lidar tipicamente com esses problemas e o tipo de produto que vai resultar; na outra, em termos de sua "aparência": uma estrutura segmentada de abordagens especializadas e fortemente classificadas que conserva um alto nível de conservação de limites e de isolamento.

Se "elevar o nível de abstração e reflexividade" é mesmo a "tendência, em longo prazo, de uma comunidade intelectual ativa" (Collins, 1998, p. 787), então as perspectivas da sociologia, neste sentido, parecem sombrias, segundo o diagnóstico de Bernstein. Entretanto, o mais surpreendente nesse relato pessimista é que, à primeira vista, ele não consegue dar conta da originalidade do próprio corpus de Bernstein, nem da maneira como ele tem se desenvolvido e modificado ao longo do tempo. Por exemplo, o próprio Bernstein (2000, p. 89-100) ressalta como os primeiros pares conceituais de sua teoria - pessoal/ posicional, instrumental/ expressivo e elaborado/ restrito - são subsumidos, num nível mais elevado de abstração, no conceito de "modalidade pedagógica":

\section{Figura 1- 0 código pedagógico}

Os códigos pedagógicos podem então ser escritos assim:

$\frac{E}{+C^{\text {ie }} /+F^{i e}}$

onde $\mathrm{E}$ éà orientação do discurso (elaborado): é a inserção dessa orientação em valores de classificação e enquadramento. Portanto, a variação da força dos valores de classificação e enquadramento gera modalidades diferentes de prática pedagógica. (Bernstein, 2000, p. 100) 
Aqui Bernstein parece estar fazendo o que seu próprio diagnóstico não admite: ele dá um exemplo de extensão vertical que contrasta com a segmentação descrita na citação anterior. Uma interpretação mínima desse aparente paradoxo é que 0 autor está simplesmente expondo as condições para um crescimento modesto de abstração no âmbito de uma linguagem especializada específica: a sua. Seja como for, é difícil não concluir que Bernstein nutria esperanças quanto a uma sociologia da educação forte, que transcendesse os limites de uma estrutura de conhecimento horizontal com uma gramática fraca. Argumentaremos que um modelo normativo para uma transição rumo a uma gramática forte está embutido em Bernstein. Na verdade, nosso argumento será que a sociologia apenas poderá sobreviver se conseguir efetuar essa transiç̧ão.

\section{O crescimento do conhecimento - possibilidades}

0 interessante é que Bernstein não era o único a desenvolver um projeto desse tipo, naquela época. Talvez o empreendimento mais ambicioso em termos de alcance tenha sido o trabalho monumental de Randall Collins, A sociologia das filosofias (Collins, 1998). Existem pontos de contato entre ambos os autores, além de eles partirem de D urkheim. 0 que essas abordagens anti-reducionistas compartilham é a preocupação em ressaltar e conceituar as propriedades intrínsecas e as estruturas de campos de produção de conhecimento e de seus princípios distintivos de relativa autonomia (ver também Abbott, 2001). No que diz respeito às análises reducionistas que têm dominado a sociologia da educação, Bernstein diz: "É como se o próprio discurso pedagógico não fosse mais do que um 'retransmissor' (relay) de relações de poder externas a ele, retransmissor cuja forma não tem efeitos sobre o que é transmitido" (1990, p. 166). O problema de teorizar e fazer pesquisas sobre o retransmissor em si constitui o ponto-chave. 0 ponto de partida é que se deve dar conta tanto da estrutura simbólica (relações internas) como da estrutura social (relações externas) de modo não-reducionista: isto é, deve-se dar conta das relações internas em si e não as amalgamando com as relações externas (como nas teorias de pontos de vista ou no relacionismo).

Como Bernstein, esses outros autores estão desenvolvendo novas maneiras, não-reducionistas, de se conceituar os campos intelec- 
tuais. A resposta de Abbott à questão do crescimento do conhecimento, por exemplo, é que a evolução conceitual adota uma forma fractal, e não uma lógica linear: "A vida cultural das ciências sociais evolui por meio de um desdobramento de distinções fractais" (Abbott, 2001, p. 157; ver também D owling, 2001). Uma estrutura fractal ocorre quando a distinção que ela traz se repete em diferentes níveis de abstração, quando a "pequena estrutura" recapitula a "estrutura maior" ou, mais especificamente, quando "a relação dos termos gerais é recapitulada nos específicos" (op. cit., p. 9).

Isso se aplica tanto a uma disciplina como um todo quanto a uma teoria (ou linguagem) específica numa disciplina. Por exemplo: cada disciplina tem um certo número reduzido de distinções-chave, centradas em idéias-chave, que Collins chama de "problemas profundos" (deep troubles):

Um problema profundo é uma doutrina que contém uma dificuldade que se autopropaga. Caminhos alternativos apresentam-se, mas cada um comporta mais enigmas. Explorar esses mistérios se torna uma dinâmica principal para que a seqüência filosófica de abstração-reflexividade tenha alcances maiores. (Collins, 1998, p. 837)

Quais são os paralelos entre idéias como "seqüências de abstração-reflexividade", "distinções fractais" e "estruturas verticais de conhecimento"? Existem duas maneiras de lidar com um "problema profundo" fractal. A primeira consiste em fundir todas as subdistinções (para cima) na distinção primeira e apurar a diferença - hoje em dia freqüentemente simplificada em formas de: dominante, hegemônico versus $\mathrm{O}$ utro subjugado. Isso vai de encontro à meta visada: "posições extremas são arrebatadoras e nobres, mas também estéreis e vãs" (Abbott, 2001, p. 89) porque levam a um enfraquecimento contínuo da gramática. A segunda consiste logicamente em elaborar uma distinção primeira, original (para baixo), em vários subníveis constituintes. Este é o caminho sistemático da elaboração teórica realista em sociologia. Bernstein exemplifica-o de modo perfeito. Tomemos sua teoria da estrutura de discurso mencionada acima, um caso exemplar para recapitular a relação da distinção em cada nó sucessivo da teoria: 


\section{Figura 2 - Modelo da estrutura imbricada da forma de discurso}

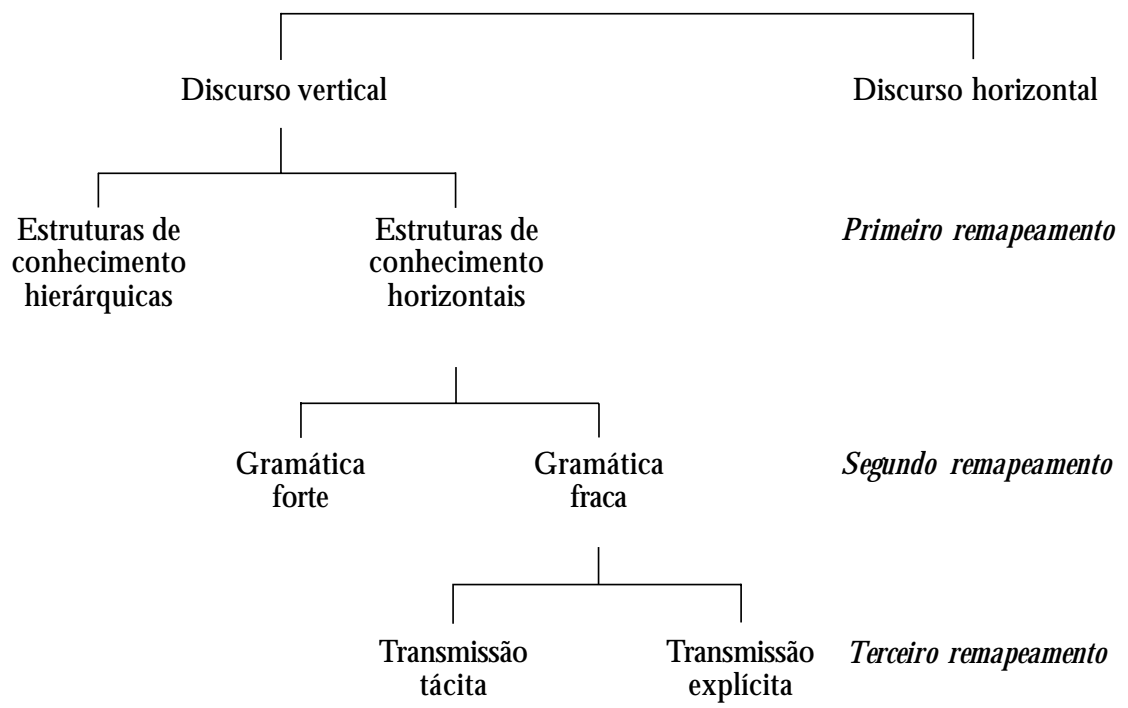

Bernstein começa por identificar o "problema profundo" fractal central da sociologia do conhecimento, a saber, a distinção entre formas de discurso, e observa que a fusão para cima, numa dicotomia rígida, sob denominações variadas, embora sempre com uma tonalidade avaliadora (como nos binários familiares concreto/ abstrato, primitivo/ lógico, ou senso comum/ conhecimento científico), funcionou como um bloqueio para a elaboração teórica. Ele se propõe explicar a cadeia fractal mostrando como a relação é recapitulada por um tipo particular de árvore fractal. 0 principal ganho conceitual trazido por esta forma de elaboração e construção de uma linguagem interna de descrição é o seguinte: ao explodir a dicotomia original desta maneira controlada, as semelhanças e as diferenças dos termos constituintes podem ser estudadas metodicamente - por exemplo, até que ponto a estrutura horizontal de conhecimento participa da verticalidade, embora ainda inte- 
gre características do discurso horizontal. 0 que temos aqui é uma elaboração de posições conceituais que contorna as simplicidades distorcedoras de uma dicotomia fracionária de duas colunas. Além disso, ela preenche a área intermediária do espectro sem desrespeitar a especificidade dos níveis.

Em sua essência, a Figura 2 é uma forma "explodida" do tipo de expressão da Figura 1, uma vez que cada um dos termos desta última poderia ser sucessivamente refinado por meio de sua própria árvore fractal para gerar conceitos cada vez mais precisos (ou, como Bernstein gostava de dizer, "delicados"), que trazem os termos mais abstratos para cada vez mais perto dos dados como "regras de reconhecimento e realização" do método de pesquisa. Votaremos a esta idéia de dispositivos "próximos aos dados".

Os jovens acadêmicos que têm contato com Bernstein pela primeira vez costumam tentar extrair algum sentido de seu pensamento fundindo de volta os galhos fractais, para cima, numa dicotomia simétrica, fazendo com que esses termos terminem rapidamente nas categorias erradas, o que gera confusão ao invés de clareza. Isso resulta em des-diferenciação e regressão conceitual. Ao longo dos anos, essa tendência foi a maior fonte de interpretações errôneas do trabalho de Bernstein, como quando, sabidamente, os conceitos iniciais de códigos elaborados e restritos foram fundidos para cima em "classe média"/ "classe operária". Bernstein raramente falou a respeito de diferenças entre classes. Sua elaboração conceitual para baixo preocupava-se com a variação dentro de uma classe e com sua regulação contextual (por exemplo, a divisão entre a nova classe média e a antiga) (Bernstein, 1977, Cap. 6, 2001). Mas o que é que possibilita esse processo de elaboração fractal? A diferença fundamental entre as estruturas de conhecimento vertical e horizontal reside em suas "linguagens de descrição".

\section{Linguagens de descrição e a lacuna discursiva - as condições para 0 crescimento}

Numa exposição detalhada dos critérios para a sua teoria, Bernstein aponta para uma característica crucial da relação entre a teoria e os dados empíricos. 
É importante acrescentar aqui que as descrições ou, antes, as regras que geram as descrições, devem conseguir apreender todas as configurações empíricas que o contexto faz surgir. Isso é crucial se quisermos evitar qualquer circularidade, como quando, no nível da descrição, a teoria constrói apenas aquilo que existe dentro de seus próprios limites. Portanto, embora derivados da teoria, os princípios de descrição devem interagir com as configurações empíricas contextuais de modo que se retenha e traduza a integridade da configuração. Assim, os princípios de descrição são os princípios-chave, pois trazem uma relação dinâmica entre níveis teóricos e empíricos... Portanto, a qualidade de uma teoria mede-se apenas pela qualidade dos princípios de descrição que origina. (Bernstein, 2000, p. 91)

Esta afirmação nos leva ao cerne do assunto. Ela define não apenas o critério central da própria teoria de Bernstein, mas também uma condição geral para qualquer teoria que aspire a uma gramática forte. Entretanto, é crucial, primeiro, ver o quanto isso é realmente importante e por quê.

A força de uma gramática e, conseqüentemente, o poder de uma estrutura de conhecimento derivam da força de suas "linguagens de descrição". Bernstein distingue duas linguagens qualitativamente diferentes na teoria e na pesquisa: a linguagem da própria teoria, uma linguagem interna de descrição (que descreve relações dentro de), e a linguagem ex terna que descreve as coisas fora da teoria que ela investiga. Se a linguagem interna constrói objetos conceituais e as relações entre eles, a linguagem externa deve construir o que deve ser considerado o referente empírico, como esses referentes se relacionam, e traduzir essas relações referenciais de volta na linguagem conceitual interna.

Essa distinção entre linguagens levanta a questão dos papéis respectivos da teoria e dos dados empíricos na elaboração teórica. D issemos que Bernstein considera que a sociologia tem uma gramática fraca. Isso significa, para a linguagem interna, uma extensão reduzida da abstração dentro da teoria e, para a linguagem externa, uma capacidade diminuta para identificar objetos empíricos de modo invariante. A sociologia é altamente competente para construir linguagens teóricas internas, mas deploravelmente inepta com linguagens externas. Pode-se até dizer que isso é o cerne do mal-estar da sociologia. A linguagem externa de descrição abre "a possibilidade de mostrar tanto as forças como os limites de uma teoria" (Bernstein, 2000, p. 139). Sem uma 
linguagem externa forte, somos privados de "um recurso crucial tanto para o desenvolvimento (teórico) quanto para a rejeição" (op. cit., p. 168). Com isso, a teoria corre incessantemente o risco de se estabilizar como uma "forma congelada" (idem, ibid.).

Estabelecemos, portanto, que a sociologia precisa de "princípios de descrição", de uma linguagem externa que vai conectar o campo de dados à teoria. Mas como conseguir realmente essa conexão? Todo aluno de pós-graduação, mais cedo ou mais tarde, há de enfrentar esse problema. Geralmente, a linguagem interna é bastante bem articulada, e 0 campo de dados claramente identificado. Entretanto, como a teoria, a linguagem interna, deveria falar com os dados? A resposta de Bernstein é que ela não pode fazer isso diretamente, porque a condensação conceitual da linguagem interna - digamos, $\pm C^{\mathrm{i} e} / \pm \mathrm{F}$ - é geral demais, longe dos dados demais, para conseguir tal intento. Um dispositivo próximo dos dados - a linguagem externa - deve ser construído para categorizar, numa grade lógica, o que, para esse campo de dados particular, deve ser considerado as instâncias identificáveis estáveis de C e F. Para progredir, portanto, cada pesquisa exige a construção de uma linguagem externa de descrição que consiste em categorias empíricas que podem ser traduzidas sem ambigüidades nas categorias conceituais da linguagem interna. Morais et al. (2001) fornecem exemplos muito claros de como isso deveria ser feito (ver também Ensor, 1999).

Teoria e dados

A explicação acima esclarece como os dados influem sobre a teoria. Mas como os dados podem estender a teoria? Em uma entrevista com Joseph Solomon, Bernstein discute isso em termos de uma "lacuna discursiva" (Bernstein \& Solomon, 2000, p. 209) entre a linguagem interna da teoria e a linguagem que descreve coisas fora dela. A linguagem externa deve não somente ser capaz de descrever o que está fora da teoria em termos relevantes para a teoria, mas também ser capaz, de algum modo, de reconhecer o que está além da teoria. Ela deve se submeter a um imperativo ontológico externo que permita que 0 que está fora "se anuncie" (idem, ibid.) e, conseqüentemente, abra as categorias da linguagem externa, assim como as relações conceituais da linguagem interna, a possíveis modificações. 
Portanto, os dados, pela linguagem externa, podem criar um excedente que exija uma extensão da teoria, para explicá-lo ou fazerlhe justiça. Contudo, do mesmo modo, a teoria é capaz de gerar possibilidades empíricas que não são, necessariamente, empiricamente evidentes. Ao discutir esse aspecto gerativo da teoria, Bernstein disse:

Costuma-se dizer que a teoria funciona produzindo dicotomias de oposição em que cada lado funciona como um tipo ideal: elaborado/ restrito, posicional/ pessoal, estratificado/ diferenciado, aberto/ fechado, visível/ invisível, coleção ou serial/ integrado. Q ue essas são formas (modelos) em oposição, concordo plenamente.Já, que são tipos ideais, discordo totalmente. Classicamente, o tipo ideal é construído juntando-se em um modelo um número de características abstraídas de um fenômeno, para fornecer um meio de analisar a presença ou a ausência desse fenômeno, e um meio de analisar seus "funcionamentos" com base em uma análise da combinação de suas características. O s tipos ideais construídos dessa maneira não podem gerar outra coisa a não ser eles próprios. Eles não são construídos por um princípio que gera conjuntos de relações dentre as quais uma forma qualquer pode ser apenas uma das formas que 0 princípio pode regular. (Bernstein, 2000, p. 123)

O s princípios gerativos da teoria criam um "elemento excedente". Os princípios possibilitam a descrição de um tipo de caso empírico (por exemplo, a sala de aula progressivista como - C - F), e geram ao mesmo tempo as outras "modalidades de prática pedagógica". Isso é historicamente contingente ao fato de qualquer uma dessas outras possibilidades realmente existir no mundo conhecido pelo teórico ou não. Em princípio, não existe nenhuma boa razão para que qualquer sociedade particular não pudesse sempre ter operado apenas com um tipo de pedagogia. A teoria pode gerar possibilidades ainda não realizadas na prática ou presentes na experiência - ela pode levantar a possibilidade de fazer as coisas de outras maneiras. 0 artigo "Códigos e pesquisa" (Bernstein, 2000, Cap. 6) tanto enfatiza os critérios da teoria como fornece uma explicação detalhada do processo de refinamento conceitual no âmbito do processo de pesquisa ao longo dos anos em que ocorreu.

As condições para qualquer crescimento do conhecimento, inclusive o da sociologia da educação, deveriam estar agora claras. O s papéis das linguagens de descrição interna e externa foram discutidos, especialmente sua natureza recíproca: a teoria e os princípios de 
descrição, bem como as linguagens interna e externa, apenas se justificam por suas relações entre si. A teoria em si é escolasticismo abstrato; o mesmo vale para a pesquisa empírica em si. Este último ponto merece ser ressaltado. A linguagem externa e seus procedimentos existem para desenvolver ou corrigir a teoria interna. Quando se tornam um fim em si, como tende a ocorrer onde a pesquisa é uma rotina e um número crescente de praticantes pelejam para chamar a atenção sobre si, então o trabalho desliza para o que Collins chama de "escolasticismo classificatório" (Collins, 1998, p. 845), o aumento quantitativo de classificações e comentários em proveito próprio, e não para prolongar a teoria, ou elevar a seqüência de abstração-reflexividade. Isso, diz Collins, é a marca da "burocratização da vida intelectual" (op. cit., p. 799). A proteção reflexiva contra o escolasticismo consiste em garantir que as conclusões são incessantemente ligadas aos pontos de tensão na teoria e, portanto, fazem-na progredir. Ilustrações repetidas que não fazem progredir a teoria entorpecem o que Collins chama de "espaço de atenção", e podem levar à paralisação da vida essencial da teoria.

\section{Conclusão}

Voltemos à nossa pergunta original: Que tipo de teoria é a de Bernstein? Para dar a resposta mais simples, para nomeá-la como uma abordagem, ela é uma forma de realismo sociológico à moda de D urkheim. Nesse sentido, ela se afasta tanto do positivismo como do construtivismo. Neste artigo, buscamos mais descrever essa teoria em termos de como ela funciona do que simplesmente nos lançarmos naquela "botânica epistemológica" de classificação que Bernstein condenou tão firmemente ao longo dos anos (Bernstein, 2000, p. 92). A teoria é uma espécie de realismo, mas podemos também descrevê-la em termos de sua gramática - sua modalidade. Essa aplicação da teoria de Bernstein sobre a teoria nos permite começar a discernir um caminho à frente para a sociologia da educação. Podemos concluir que a via principal para o crescimento do conhecimento sociológico reside na elaboração contínua de linguagens/ teoria internas. Uma condição indispensável para elaborá-las é o desenvolvimento e a implementação de linguagens externas, e é aqui que, historicamente, a sociologia tem se mostrado mais fraca. Uma condição para sua boa saúde futura reside 
em trabalhos empíricos conjuntamente desenvolvidos e rigorosamente ligados à teoria. Duas práticas-chave degenerativas devem ser evitadas. 0 desenvolvimento conceitual interno acaba quando a elaboração fractal se funde na dicotomia original; e a ilustração empírica torna-se estéril quando está desvinculada da elaboração conceitual.

Contudo, ainda restam bons motivos, nas condições atuais, para empreendermos o exercício taxonômico que situa as teorias como abordagens. Isso tem a ver com o problema levantado acima a respeito das dificuldades para ver uma forma de conhecimento com uma gramática forte no interior de um campo caracterizado por uma gramática fraca ver a teoria de Bernstein como a teoria que ela é, por exemplo. Primeiro, a tarefa consiste em anunciar que ex iste uma alternativa à dicotomia simplificadora do positivismo ou do construtivismo (ou em educação, "tradicionalismo" versus "progressivismo"). A abordagem realista permite uma revalorização radical do campo e do modo em que suas posições e relações são percebidas e a relação entre teoria e pesquisa é entendida. Contra o positivismo, 0 realismo insiste na primazia da teoria sobre a experiência, mas, contra o construtivismo, ele reconhece a disciplina ontológica da lacuna discursiva - a realidade se "anuncia" a nós também como sendo construída por nós. É precisamente a disciplina da "lacuna discursiva" que foi renegada ou abandonada por um imenso leque de perspectivas pós-modernas, multiculturalistas e pós-colonialistas, geralmente sustentadas por várias interpretações de pensadoreschave como Foucault e D errida, que, hoje em dia, agrupam-se perto do centro do empreendimento sociológico. Para Bernstein e outros realistas, contudo, a busca de validade dentro do espaço criativo da lacuna discursiva deve se estender, como disse Habermas, numa análise surpreendentemente paralela, "além da fronteira do texto" (Habermas, 1995, p. 223). O trabalho de Basil Bernstein surge como um marco exemplar iluminando o caminho.

Recebido em agosto de 2003 e aprovado em setembro de 2003.

\section{Referências bibliográficas}

ABBOTT, A. Chaos of disciplines. Chicago: Chicago University, 2001.

BERNSTEIN, B. Class, codes and control. London: Routledge, 1977. v.3 
BERNSTEIN, B. The structuring of pedagogic discourse. In: BERNSTEIN, B. Class, codes and control. London: Routledge, 1990. v.4.

BERNSTEIN, B. Pedagogy, symbolic control and identity: theory, research, critique. London: Taylor \& Francis, 1996.

BERNSTEIN, B. Pedagogy, symbolic control and identity: theory, research, critique. Rev. ed. Oxford: Rowman \& Littlefiel, 2000.

COLLINS, R. The sociology of philosophies: a global theory of intellectual change. Cambridge, Mass.: Belknap, 1998.

D OWLING, P. Social activity theory. London: University Institute of Education, 2001. Disponível em: <http:/ / www.ioe.ac.uk/ ccs/ dowling> Acesso em: nov. 2003.

ENSOR, P. 1999. Unpublished PhD thesis, University of London.

MATON, K. Languages of legitimation: the structuring significance for intellectual fields of strategic knowledge claims. British Journal of Sociology of Education, Oxfordshire, v. 21 n. 2, p.147-167, 2000.

MO ORE, R. Extended review: Richard Hoggart, 'the way we live now'. British Journal of Sociology of E ducation, Oxfordshire, v. 17, n.4, p.521-530, 1996.

MOORE, R.; MATON, K. Founding the sociology of knowledge: Basil Bernstein, intellectual fields and the epistemic device. In: MoRAIS, A. et al. (Ed.). Towards a sociology of pedagogy: the contribution of Basil Bernstein to research. New York: Peter Lang, 2002.

MOORE, R.; MULLER, J. The discourse of "voice" and the problem of knowledge and identity in the sociology of education. British Journal of Sociology of E ducation, Oxfordshire, v. 20, n. 2, p.189-206, 1999.

MORAIS, A. et al. (Ed.). Towards a sociology of pedagogy: the contribution of Basil Bernstein to research. New York: Peter Lang, 2001.

MULLER, J. Reclaiming knowledge. London: Routledge; Falmer, 2000 . 
MULLER, J. Progressivism redux: ethos, policy, pathos. In: KRAAK, A.; Young, M. (Ed.). E ducation in retrospect: policy and implementation since 1990. Pretoria: Human Sciences Research Council; London: Institute of Education, University of London, 2001.

YOUNG, M.F.D. Rescuing the sociology of knowledge from the extremes of voice discourse: towards a new theoretical basis for the sociology of the curriculum. British Journal of Sociology of Education, Oxfordshire, v. 21, n. 4, p. 523-536, 2000. 